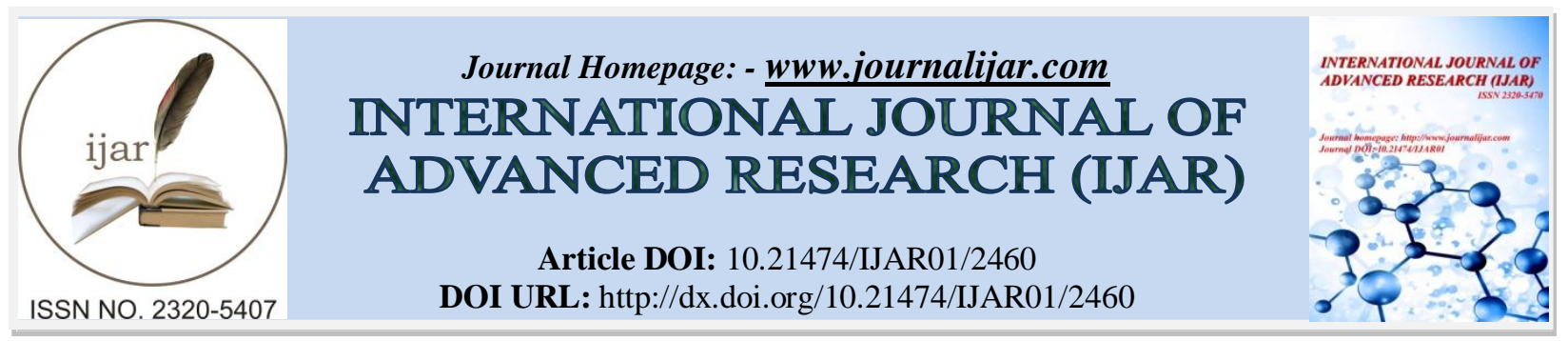

\title{
RESEARCH ARTICLE \\ QUANTITATIVE AND QUALITATIVE GUT CONTENT ANALYSIS OF MACROBRACHIUM ASSAMENSE PENINSULARE FROM RAWASAN STREAM OF GARHWAL HIMALAYA, UTTARAKHAND, INDIA.
}

\author{
Koshal Kumar ${ }^{1}$, C. B. Kotnala ${ }^{1}$ and Anita Rawat Rana ${ }^{2}$. \\ 1. Department of Zoology, Campus Pauri, H.N.B Garhwal (A Central University) Uttarakhand India-246001. \\ 2. Department of Zoology, Govt. P.G. (Autonomous) College Rishikesh, Uttarakhand India-249202.
}

\section{Manuscript Info}

Manuscript History

Received: 23 October 2016

Final Accepted: 21 November 2016

Published: December 2016

Key words:-

Macrobrachium assamense peninsulare, natural food, gut content analysis, Rawasan stream

\section{Abstract}

Food is an essential for any organism, for growth, reproduction and culture aspects. Study on food and feeding of Macrobrachium assamense peninsulare has been carried out by quantitative and qualitative gut content analysis methods. Prawns were collected monthly from August 2013 to July 2015 and analyses of stomach contact were made to know the natural food of these prawns. From the overall analysis it has been reported that these prawns are omnivorous in nature and generally eat up the microscopic food, either animal or plant matters. Food consists of fragments of aquatic plants, algae, animal matter, diatoms, sand grains and highest percentage of amorphous mass. Results indicate that the adults are mostly predators of benthic invertebrates rather than detritus feeders/scavengers.

Copy Right, IJAR, 2016,. All rights reserved.

\section{Introduction:-}

Macrobrachium assamense peninsulare, a minor prawn, found in the low velocity water bodies in the Uttarakhand, are economically used as food by the local habitants. However, their supply is primarily totally from the wild catch and is limited due to the inadequate source of availability in their natural habitat. The members of genus Macrobrachium are adapted themselves to a wide range of food of both plant and animal origin. It has been shown from earlier study that these minor prawns are omnivores in their feeding habits (Sharma and Subba, 2005).

Information about the natural food of the prawn and their nutritional characteristic is essential and act as an evidence for artificial diet during aquaculture. Due to mass culture practices in prawn, the significance of artificial food is recognized. The selection of experimental diet has frequently been assessed in term of food conservation ratio (Froster, 1976; Reddy \& Shakuntala, 1986). Accurate diet and feeding habits description helps to understand the tropical interaction of aquatic animals with their food web. Feeding is the most important function of an organism and most of the time in their daily life devoted by these organisms in the search of proper food. Although many authors have studies food and feeding of prawn species earlier (Chopra, 1939; Panikkar, 1952; Sharma \& Subba, 2005; Hall, 1962; Thomas, 1972; Marte, 1980; Khan, et al., 2001; Basker et al., 2013; Bakhtiyar et al., 2014)

This paper deals with the study of stomach contents of Macrobrachium assamense peninsulare collected from its natural habitat from Rawasan stream to know the natural food composition.

Corresponding Author:- Anita Rawat Rana.

Address:- Department of Zoology, Govt. P.G. (Autonomous) College Rishikesh, Uttarakhand India249202. 


\section{Materials and Methods:-}

To understand the food intake of Macrobrachium assamense peninsulare the qualitative and quantitative analysis of gut contents were made on monthly basis for an interval of two years (2013-2015). For this study 10 male and female were fixed in $70 \%$ alcohol soon after their capture, in order to stop the digestion of food in the alimentary canal (Williams, 1981) and brought to the laboratory for further analysis. In the laboratory before processing for the microscopic examination of the food contents, total weight of the individual intact prawn and that of its gut contents were recorded separately. In each specimen the carapace was opened from the dorsal side of the body and gut was removed carefully. A visual examination of fullness of intestinal bulb was also made immediately after its removal (Devi et al., 2013). The microscopic analysis was carried out as hurriedly as possible and was never overdue from more than 4 day after capturing the animal.

\section{Analysis of Gut contents:-}

In prawn, the food which reaches the gut is very fine crushed and is meshed due to the presence of powerful mandible. It is further churned in the mill itself and thus, the food items were identified up to the level which was possible. Different type of food item and their percentage was calculated on the basis of fractional analysis, by taking $1 \mathrm{ml}$ of well shaken and thoroughly mixing stomach content suspension from petri dish into the Sedgewick rafter chamber and examined under binocular microscope to obtain percentage composition of different food items. Various food items were examined using binocular microscope and identified to the lowest possible taxonomical level with the help of keys and photographs provided by Ward and Whipple (1959); Needham and Needham (1962) and (APHA, 2012). The quantitative analysis was made and point was given purely on the basis of observation of food items.

\section{Observations:-}

\section{Food and feeding habits:-}

The mode of feeding in Macrobrachium assamense peninsulare was observed visually in the field during the study. It was observed that prawn, by habit is an omnivorous species and exhibits feeding activity in day time in comparison to the other species. These prawns are also shy in nature and hide them self in their micro habitats and found under the stones, crevices near the bank of the stagnant water during study.

\section{Quantitative study:-}

Monthly visual observation was also made and recorded the degree of fullness (\%) of gut in Macrobrachium assamense peninsulare (Table 2). It is clearly proved that fullness of gastric content is directly related with seasonal variation and $100 \%$ fullness of gastric content was never observed during the study period of two years. Quantitative analyses revealed less than $6 \%$ population as empty stomach, 59.8\% of stomach as actively fed including, $100 \%$, $75 \%$ and $50 \%$ diet contents and poorly fed having $40.9 \%$ of stomach including, trace, empty and $25 \%$ gut content.

\section{Qualitative study:-}

On the basis of microscopic examination of the gastric content, food was identified and categorized into seven groups viz., those containing fragments of aquatic plants, algae, animal matter, diatoms, sand grains and unidentified organisms. Different food items percentage in male and female prawn shown in Fig 1 (a \& b). Composition of gut contents of Macrobrachium assamense peninsulare in relation to size groups were presented in the Table 1. During the observation no sex related trend with relation to different food types was observed. During the microscopic observation in the laboratory several food items identified from gut contents were recorded as.

a. Fragments of aquatic plants: These types of food comprised of different types of green grass, parts of seeds, leaves and root materials often found in the gut of the both sexes in all size groups. It ranked fifth (7\%) in female and sixth $(5 \%)$ in male among food items during study.

b. Fragment of animals: Fragments of animals were observed throughout the year during the study and ranked second both in female and male prawn gut i.e. (19\%) and (23\%) respectively. Animal matter consisted of parts of cuticles, exoskeletons and parts of polychaetes represented by bristles, jaw, legs and fragment of body parts, fragments of zooplanktons such as antenna, pleopods and some parts of aquatic insects their nymphs and larva.

c. Algae: Fragment of green and blue green algae were observed throughout the study in both sexes and also in all size groups. Algae forms the third important constituent of prawn food item having (19\%) in female and (14\%) in male. The most important genera of algae were Cladophora, Anabaena, Zygnema, Volvox, Oscillataria etc. 
d. Diatom: Represented mainly by Fragilaria, Pinularia, Nitzchia, and Gomphonema and ranked fourth among the food items in Macrobrachium assamense peninsulare having (8\%) in male and (7\%) in female.

e. Unidentified organisms: These were probably parts of the undigested food items of both aquatic plants and animal. These were observed in the gut throughout the study periods and dominated in the size group of 20-30 $\mathrm{mm}$ body length prawn and ranked fifth among the food items in male (6\%) and sixth (4\%) in female.

f. Amorphous mass: Amorphous mass or unidentified debris comprised of fragments of decomposing organic matter which could not be accurately identified due to their tiny size and poor physical appearance. This types of food items showed the dominance in gut content, i.e. male (44\%) and female (41\%) in Macrobrachium assamense peninsulare and was recorded maximum in $20-30 \mathrm{~mm}$ size group in male $(43.2 \%)$ in male and (41\%) in female individual.

g. Sand grains: Sand grains were found in inadequate percentage 1- $2 \%$ in the gut of both sexes throughout the study. This item was possibly an accidental inclusion along with other food items, even though M. a. peninsulare is bottom feeder were mostly prefer dead and decay matter.

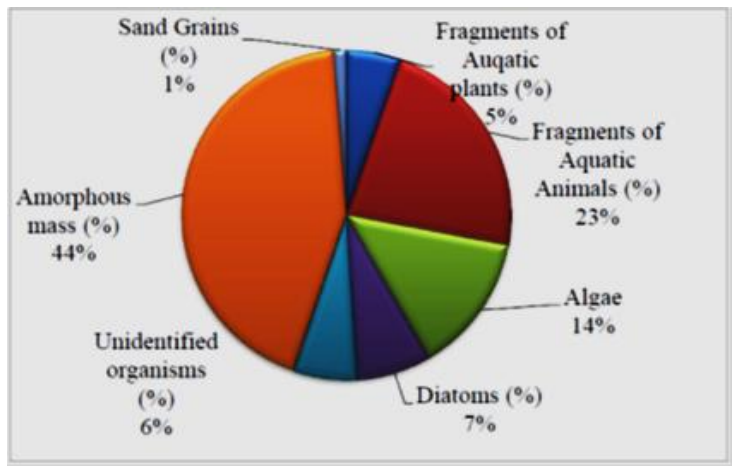

(a) Female

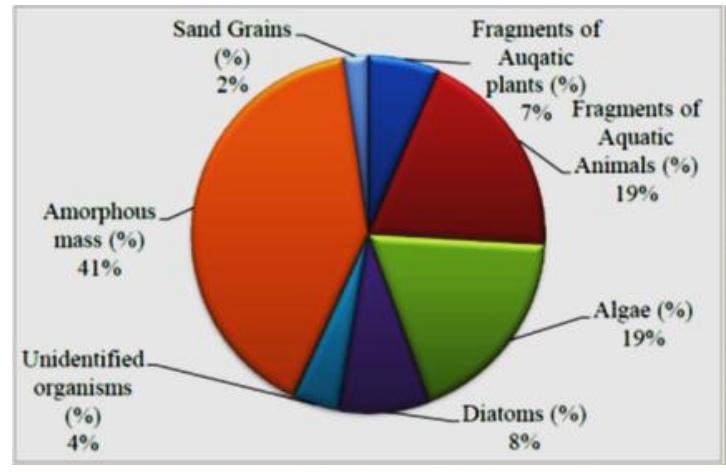

(b) Male

Fig. 1:- Percentage of food items (\%) in Macrobrachium assamense peninsulare

Table 1:- Percentage composition of gut contents of $M$. assamense peninsulare in relation to size groups

\begin{tabular}{|c|c|c|c|c|c|c|c|c|}
\hline $\begin{array}{l}\widehat{\widehat{E}} \\
.5 \\
.5\end{array}$ & 㝘䒿 & 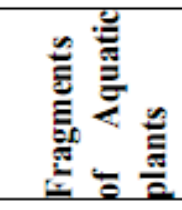 & 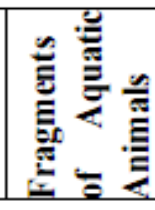 & 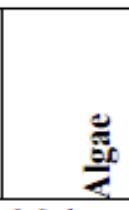 & & 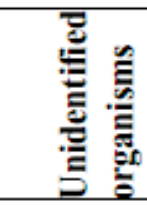 & 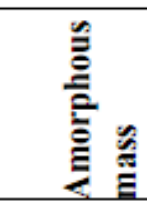 & 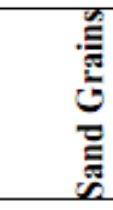 \\
\hline \multicolumn{9}{|c|}{ Male } \\
\hline $20-30$ & 16 & 5.3 & 23 & 13.6 & 7.3 & 6.2 & 43.2 & 1.3 \\
\hline $30-40$ & 60 & 9.3 & 32 & 8.78 & 4.6 & 4.9 & 37.9 & 3 \\
\hline $40-50$ & 70 & 11 & 34 & 11.3 & 3 & 3.3 & 35.2 & 2.8 \\
\hline $50-60$ & 39 & 10 & 32 & 15.7 & 7 & 1.8 & 32.6 & 1.5 \\
\hline $60-70$ & 4 & 12 & 37 & 4.22 & 4 & 3.8 & 34.6 & 5.6 \\
\hline \multicolumn{9}{|c|}{ Female } \\
\hline $20-30$ & 13 & 6.6 & 19.4 & 19 & 8.3 & 4.26 & 41 & 2.3 \\
\hline $30-40$ & 87 & 8.6 & 21.4 & 15 & 9 & 3.23 & 40 & 3.4 \\
\hline $40-50$ & 84 & 10 & 23.1 & 12 & 7.5 & 2.72 & 42 & 2 \\
\hline $50-60$ & 27 & 11 & 33.2 & 9.6 & 6.8 & 2.92 & 35 & 1.8 \\
\hline $60-70$ & - & - & - & & - & - & - & - \\
\hline
\end{tabular}


Table 2:- Monthly variation in the degree of fullness of guts (\%) in M. assamense peninsulare

\begin{tabular}{|c|c|c|c|c|c|c|c|}
\hline \multirow[b]{3}{*}{ Months } & \multirow{3}{*}{$\begin{array}{l}\text { No. Of } \\
\text { Examined }\end{array}$} & \multicolumn{6}{|c|}{ Degree of fullness (\%) } \\
\hline & & \multicolumn{3}{|c|}{ Poor fed } & \multicolumn{3}{|c|}{ Actively fed } \\
\hline & & Empty & Trace & 25 & 50 & 75 & 100 \\
\hline August & 10 & 9.76 & 11.89 & 16.96 & 29.78 & 31.78 & - \\
\hline September & 10 & 11.34 & 11.26 & 20.98 & 39.5 & 17.35 & - \\
\hline October & 10 & 6.34 & 12.45 & 27.56 & 26.55 & 27.67 & - \\
\hline November & 10 & 2.67 & 9.95 & 18.79 & 45.6 & 23.45 & - \\
\hline December & 10 & 0 & 13.78 & 25.56 & 35.56 & 25.45 & - \\
\hline January & 10 & 0 & 13.75 & 27.33 & 21.95 & 39.78 & - \\
\hline February & 10 & 5.98 & 14.43 & 19.75 & 24.46 & 35.98 & - \\
\hline March & 10 & 4.89 & 18.45 & 17.78 & 19.78 & 39.43 & - \\
\hline April & 10 & 9.67 & 18.57 & 15.47 & 14.26 & 42.56 & - \\
\hline May & 10 & 12.4 & 15.03 & 17.02 & 15.22 & 40.78 & - \\
\hline June & 10 & 0 & 16.67 & 23.35 & 17.87 & 42.34 & - \\
\hline July & 10 & 0 & 16.22 & 24.56 & 14.68 & 45.67 & - \\
\hline Total & 120 & 5.2542 & 14.371 & 21.259 & 25.434 & 34.353 & - \\
\hline
\end{tabular}

\section{Discussions:-}

Diet of Macrobrachium assamense peninsulare is generally microscopic, containing minute animal and plant matter showing its omnivorous nature. It is evident from gut content analysis that the organic detritus (unidentified debris) appears quite regular in the diet of the Macrobrachium assamense peninsulare (Table 1) throughout the study period in different size groups although its efficacy as food source seen to be important to grown-up prawns when it leads to benthic existence. Organic detritus was readily consumed when the other preferred food items were less available. Pringle et al. (1993) and Pringle (1996) mentioned that the decapods crustaceans are omnivores and detritivoros. Present finding also get support from the studies on feeding habits and food of $M$. acanthurus (Albertoni et al., 2003a), M. lamarrei (Sharma and Subba, 2005), M. vollenhovenii (Jimoh et al., 2011) and M. carcinus (Lima et al., 2014) which were found to be omnivorous in nature. Quantitative estimation of gut contents of Macrobrachium assamense peninsulare is in agreement with the result of Raman (1967); Rao (1967); Ling (1969) and Coasta and Wanninayake (1986), who have reported that prawn are omnivores in feeding habitat. Bakhtiyar et al. (2014) also reported that the $M$. dayanum has been categorized as detriti-omnivorous feeding on both animal and plant matter with detritus as dominant food items and similar observation was recorded in Macrobrachium macrobrachion in Nigeria by Joseph et al. (2013).

Gut content of Macrobrachium assamense peninsulare consisted of fragments of aquatic plants, fragments of aquatic animals, algae, diatoms, amorphous mass, sand grains and unidentified organisms, which represented different trophic level. All types of food item were observed throughout the study period in variable proportion. In comparison to the observation of Subramanyam (1963a) and in agreement with Gopalkrishnan (1952), neither the size nor the sex had any relationship with the feeding habits of the prawn and the similar observation was observed in our study in Rawasan prawn. Present study was also comparable with the finding of Lee et al. (1992) analysis from gut contents of shrimp Lucifer faxoni. Dall (1968) had reported that the gut contents of various penaeid shrimps i.e. M. accleayi, P. plebejus, P. osculentes and P. merguiensis were mainly comprised of animal body parts (Jaw, legs, chitin fragments and seta) and some unidentified matters. Panikker (1952) reported food of young penaeid as of tiny organism, alga and detritus. Animals are classified as herbivorous, omnivorous and carnivores on the base of food type they eat (Chopra, 1939). Presence of fish scale by accidental entry along with detritus was observed in the gut content of $M$. rosenbergii (Raman, 1967) and M. equidens (Murthy \& Rajagopal, 1990), whereas as no such material were reported from the gut contents of the Macrobrachium assamense peninsulare during the study.

Rao (1967) reported that the $M$. rosenbergii eat up their exuvia after molting and Natraj (1947) also made similar observation in $P$. idea. During present study, we also observed $M$. assamense peninsulare by eating exuvia during the laboratory inspection in aquarium and sometime in the field observation. Murthy and Rajagopal (1990) recorded that in $M$. equidens the most of the food items consist of crustacean appendages, some parts of decay organic matter, sand and mud similar observations were recorded in our study. 
The percentage of empty stomach showed an increasing trend in $M$. assamense peninsulare toward the end of the onset of the breeding season and it was due to the less food intake by female prawn due to gonadal maturation, which occupy major portion of the cephalothorax and this is well compared with the studies of M. malcolmsoni Ibrahim (1962) where in a reduced feeding was noticed in mature female.

\section{Acknowledgement:-}

The Authors' are very much grateful to Prof. A. K. Dobriyal, HOD of Zoology and biotechnology, Director of Campus Pauri, H.N.B Garhwal (A Central University), Pauri Garhwal Uttarakhand for encouragement and facilities provided to carry out this work and also to UGC New Delhi for providing National Fellowship For Higher Education to first author Mr. Koshal Kumar to meet the contingent expenditure.

\section{References:-}

1. Albertoni E.F., C. Pama-Silva and F.A. Esteves, (2003a). Overlap of dietary niches and electivity of three shrimp species (Crustacea, Decapoda) in tropical coastal lagoon (Rio de Janeiro, Brazil). Revista Brasileira de Zoologia, 2003a; 2091:135-140.

2. APHA, (2012). Standard method for the examination of water and waste water. APHA, AWWA, WPEC, $22^{\text {th }}$ edition, New York

3. Bakhtiyar, Y., R. Lakhnotra and S. Langer, (2014). Natural food and feeding habits of a locally available freshwater prawn Macrobrachium dayanum (Henderson) from Jammu waters, North India. International Journal of Fisheries and Aquatic Studies; 2(3): 33-38

4. Baskar, S. N.Narasimhan, G.Swamidass Daniel, R.Ravichelvan, M.Sukumaran, T.Anandaraj (2013). Food and Feeding Habits of Penaeusmonodon(Fabricius) from Mallipattinam Coast in ThanjavurDist, Tamil Nadu, India . International Journal of Research in Biological Sciences 3(1) : 1-4

5. Chopra, B., (1939). Some food prawns of India and their fisheries. J. Bombay Nat. Hist. Soc., 41: $221-234$.

6. Coasta, H.H. and T.B. Wanninayake, (1986). Food, feeding and fecundity of the giant fresh water prawn, Macrobrachium rosenbergii from a natural habitat in Sri Lanka. The first Asian fisheries forum, Pp. 555-558.

7. Dall, W., (1968). Food and feeding of some Australian Penaeid Shrimp. FAO Fish. Rep. 2:251-258.

8. Devi P.L., D.G. Nair and A. Joseph, (2013). Habitat ecology and food and feeding of the herring bow crab, Veruna litterata (Fabricius, 1798) of Cochin backwaters Kerla India. Arthropods 2(4): 1782-188.

9. Froster, J.R.M. (1976). Studies on the development of compounded diets for prawn. Int. conference on aquaculture nutrition. Delaware sea programme and U.S/Japan aquaculture panel. UJNR, pp 229-248.

10. Gopalkrishnan, V., (1952). Food and feeding habit of penaeus indicus. J. Madras Univ., B 22 69-75.

11. Hall, D.N.F. (1962). Observations on the taxonomy and biology of some Indo-West-Pacific Penaeidae (Crustacea, Decapoda). Fish. Publ. Colon. Off. Lond., (17): 229 pp.

12. Ibrahim, K.H. (1962). Observations on the fishery and biology of the freshwater prawn Macrobrachium malcolmsonii of the River Godavari. Ind. Fish.,9(2): 433-467

13. Jimoh, A.A, E.O. Clarke, O.O. Whenu and H.B. Adeoye, (2011). Food and feeding habits of the African river prawn (Macrobrachium vollenhovenii, Herklots, 1857) in Epe Lagoon, southwest Nigeria. Int. Journal of Fisheries and Aquaculture 2011; 3(1):10-15.

14. Joseph, I., A.E. Bassey, E. George, U. George, (2013). FeedingHabits of the Brackish River Prawn (M. macrobrachion, Herklots, 1857) from Great Kwa River, Obufa Esuk Beach, Calabar, Cross River State, Nigeria. Journal of Natural Sciences Research, Vol.3, No.9.

15. Khan R.A. N. Aravindan and A. Kalavat, (2001). Distribution of two post-larvae species of commercial prawns (Fenneropenaeus indicus and Penaeus monodon) in a coastal tropical estuary. J. Aqua. Sci. 16(2): 99-104.

16. Lee, W., Y. Omori, and R. Peck, (1992). Growth, reproduction and feeding behavior of the planktonic shrimp, Lucifer faxoni Borraidele, off the Texas coast. Journal of Plankton Research, vol. 14, no. 1, p. 61-69.

17. Lima, J.D.F, J.D.S. Garcia and T.C.D. Silva, (2014). Natural diet and feeding habits of a freshwater prawn (Macrobrachium carcinus: Crustacea, Decapoda) in the estuary of the Amazon River. Acta Amazonica. 44(2):235-244.

18. Ling, S.W., (1969). The general biology and development of Macrobarchium rosenbergii (de man). FAO Fish reproduction $57(3)$ 589-606.

19. Marte, C. L. (19800. The food and feeding habit of Penaeus monodon Fabricius collected from Makato River, Aklan,Philippines (Decapoda Natantia). Crustaceana, 38(3): 225-236. 
20. Murthy, D. K. and K.V. Rajagopal, (1990). Food and feeding habits of the freshwater prawn Macrobrachium equidens (Dana). Indian J. Anim. Sci., 60 (1): 118-122.

21. Natraj, S. (1947). Preliminary observation on the bionomics reproduction and embryonic stages of Palaemon idea, Heller. Rec Indian Mus 45 (1) pp: 89-96

22. Needham, P.R. and J.G. Needham, (1962). A guide to the study of freshwater biology $5^{\text {th }}$ (ed.) Holden Day Incorporation .

23. Panikker, N.K., (1952). Possibilities of further expansion of fish and prawn culture practices in India. Curr. Sci., 21: 29-33.

24. Pringle C.M. (1996). Atyid shrimps (Decapoda: Atyidae) influence the spatial heterogeneity of algal communities over different scales in tropical montane streams, Puerto Rico. Freshwater Biology, 35(1):125140 .

25. Pringle, C.M., G.A. Blake, A.P. Covich, K.M. Buzby and A. Finley, (1993). Effects of omnivorous shrimp in a montane tropical stream: sediment removal, disturbance of sessile invertebrates and enhancement of understory algal biomass. Oecologia, 93(1):1-11.

26. Raman, K. (1967). Observation of the fishery and biology of the giant freshwater prawns Macrobarchium rosenbergii de Man. Proc. Symp. Crustacea, Mar Biol. Ass. India, Part-2, 649-669.

27. Rao, R.M., (1967). Studies on the biology of Macrobrachium rosenbergii ( de Man) of the Hoogly estuary with notes on its fishery. Proc. B, Biol. Sci. 33:252-279.

28. Reddy, S. R. and K. Shakuntala, (1986). Use of myside as a food for culture of juvenile peneaus merguienisis . In: Biology of benthic marine organisms (M. F. Thomson R Sarojanni and R. Nagabhushanam eds) Oxford IBH, New Delhi pp 359-363.

29. Sharma, A. and B.R. Subba, (2005). General biology of freshwater prawn, Macrobrachium lamarrei (H. Milne-Edwards) of Biratnagar, Nepal. Our nature 3(1):31-41.

30. Subramanayam, C.B., (1963a). Note on the bionomics of the penaeid prawn metapenaeus affinis (Milne Edwards) of Malabar coast. Ind. J. Fish., 10:11-22.

31. Thomas, N. M. (1972). Food and feeding habits of Penaeus monodon Fabricius from Korapuzha estuary. Indian J. fish., 19(1\&2):202-204.

32. Ward, H.B. and G.C. Whipple, (1959). Fresh Water Biology $2^{\text {nd }}$ (edn.) John Wily and Sons New York USA.

33. Williams, M.J., (1981). Methods for analysis of natural diet in portunid crabs (Crustacean: Decapoda: Portunidae). J. of Experimental Marine Biology and Ecology 52 :103- 113. 